\title{
Metodologia para teste de tetrazólio em sementes de Amburana cearensis (Allemão) A.C. Smith
}

\author{
GUEDES, R.S. ${ }^{1 *}$; ALVES, E.U. ${ }^{1}$; GONÇALVES, E.P. ${ }^{2}$; VIANA, J.S. ${ }^{2}$; SILVA, K.B. ${ }^{1}$; GOMES, M.S.S. ${ }^{1}$ \\ ${ }^{1}$ Universidade Federal da Paraíba, Caixa Posta 02, CEP:58397-000, Areia-Brasil *roberta_biologa09@yahoo.com.br \\ ${ }^{2}$ Universidade Federal Rural de Pernambuco, Unidade Acadêmica de Garanhuns, Avenida Bom Pastor, s/n, Boa \\ Vista, CEP: 55296-901, Garanhuns-Brasil
}

\begin{abstract}
RESUMO: Objetivou-se com este trabalho estudar a metodologia do teste de tetrazólio para sementes de Amburana cearensis (Allemão) A.C. Smith, determinando as melhores condições de pré-umedecimento, bem como temperatura, período de coloração e concentração da solução de tetrazólio. Avaliou-se a coloração das sementes intactas e escarificadas (lixadas), ambas com tegumento, diretamente na solução de tetrazólio nas concentrações de 0,025; 0,050; 0,075 e $1 \%$ a 35 e $40^{\circ} \mathrm{C}$, por 12 e $24 \mathrm{~h}$ no escuro. Verificou-se o pré-umedecimento para retirar 0 tegumento utilizando-se sementes intactas e escarificadas, as quais foram imersas diretamente em água e submetidas a embebição em papel toalha e por 12, 24, 36 e 48 horas em temperaturas de 35 e $40^{\circ} \mathrm{C}$. Após a determinação do método para retirar o tegumento os embriões foram submetidas à coloração em solução de tetrazólio nas concentrações de 0,025; 0,050; 0,075 e $1 \%$. Com os resultados obtidos verificou-se a necessidade da retirada total do tegumento para que ocorra a coloração e que a temperatura de $40^{\circ} \mathrm{C}$ é prejudicial para a embebição no préumedecimento. $O$ teste de tetrazólio nas sementes de $A$. cearensis deve ser realizado com 0 pré-umedecimento das sementes escarificadas (lixadas) e imersas diretamente em água por 24 horas, na temperatura de $35^{\circ} \mathrm{C}$, para posterior retirada total do tegumento. E para atingir a coloração ideal os embriões devem ser imersos em solução de tetrazólio a 0,05\% por 3 horas, a $40^{\circ} \mathrm{C}$.
\end{abstract}

Palavras-chave: cumaru, temperatura, concentração, plantas medicinais, sementes

\begin{abstract}
Methodology for tetrazolium test in Amburana cearensis(Allemão) A.C. Smith seeds. This work aimed to evaluate the methodology of tetrazolium test in Amburana cearensis (Allemão) A.C. Smith seeds, establishing the best pre-moistening conditions, as well as temperature, coloration period and tetrazolium solution concentration. The coloration of intact and scarified (sanded) seeds, both with tegument, was directly evaluated in tetrazolium solution at the concentrations of $0.025 ; 0.050 ; 0.075$; and $1 \%$, at 35 and $40^{\circ} \mathrm{C}$, for 12 and $24 \mathrm{~h}$ in the dark. Premoistening to remove the tegument was evaluated by using intact and scarified seeds, which were directly immersed in water and subjected to imbibition in paper towel for $12,24,36$, and 48 $\mathrm{h}$ at 35 and $40^{\circ} \mathrm{C}$. After establishing the method to remove the tegument, embryos were subjected to coloration in tetrazolium solution at the concentrations of $0.025 ; 0.050 ; 0.075$; and $1 \%$. Based on the obtained results, the complete tegument removal is needed for coloration; besides, the temperature of $40^{\circ} \mathrm{C}$ is harmful for imbibition during pre-moistening. The tetrazolium test in $A$. cearensis seeds should be performed including pre-moistening through direct immersion of scarified (sanded) seeds in water for $24 \mathrm{~h}$ at $35^{\circ} \mathrm{C}$ for later complete tegument removal. To achieve the ideal coloration, embryos must be immersed in tetrazolium solution at $0.05 \%$ for $3 \mathrm{~h}$ at $40^{\circ} \mathrm{C}$.
\end{abstract}

Key words: "cumaru", temperature, concentration, medicinal plants, seeds

\section{INTRODUÇÃO}

As plantas medicinais são recursos genéticos que compõem parte da biodiversidade, deste modo é necessário estabelecer estratégias eficazes para a conservação in situ e ex situ dos recursos genéticos, coletando, integrando e sistematizando informações disponíveis sobre os

Recebido para publicação em 09/06/2008

Aceito para publicação em 08/12/2009

Rev. Bras. Pl. Med., Botucatu, v.12, n.1, p.120-126, 2010. 
diferentes biomas e os recursos naturais (Mendonça et al., 2006). Em virtude da utilização de plantas medicinais da caatinga na medicina popular, é necessário estudar melhor as espécies nativas quanto à propagação e à análise de sementes, de modo a fornecer subsídios aos plantios racionais e a revegetação de áreas de extrativismo e preservação ambiental, bem como desenvolver métodos para avaliação rápida da qualidade fisiológica da semente, que permitam rapidamente a tomada de decisão quanto ao uso ou descarte de sementes destinadas à produção de mudas.

Amburana cearensis (Allemão) A.C. Smith, pertencente à família Fabaceae, é uma árvore de caule ereto, que chega a atingir 10 a 12 metros de altura (Lorenzi, 1992). A espécie é também conhecida como cerejeira e, devido as qualidades madeireiras, tem sido explorada nos locais de ocorrência até a exaustão, na movelaria fina, esculturas e marcenaria em geral, estando listada como espécie ameaçada de extinção (IBAMA, 2008).

Além disso, é empregada na medicina popular, sendo a casca da árvore e as sementes utilizadas na produção de medicamentos populares destinadas ao tratamento de afecções pulmonares, tosses, asma, bronquite e coqueluche (Berg, 1986; Lorenzi \& Matos, 2002). Da casca do caule já foram isoladas várias substâncias, incluindo cumarina, isocampferídio, fisetina, alfalona e amburosídio A, que estão relacionadas às atividades antinociceptiva, antiinflamatória e relaxante muscular (Canuto, 2002).

Normalmente, o teste de germinação não têm sido suficiente para a identificação primorosa de lotes de diferentes níveis de qualidade fisiológica (MarcosFilho et al., 1987), devido ao fato de ser conduzido sob condições controladas e não subsidiar informações sobre o vigor das sementes. Tem se evidenciado também neste método sérias limitações, principalmente para espécies florestais, cujas sementes geralmente exigem longo período para germinar e apresentam baixa capacidade de armazenamento.

Para determinar o vigor e a viabilidade de sementes, podem ser utilizados vários testes. Dentre os testes indiretos considerados rápidos, o teste de tetrazólio vem se destacando por ser uma alternativa viável para fornecer informações aos agricultores ou viveiristas. O teste vem sendo empregado, rotineiramente, na avaliação rápida da viabilidade de sementes de várias espécies, principalmente daquelas que necessitam de longos períodos para germinar, como é o caso de algumas frutíferas, forrageiras e florestais. Assim, o teste de tetrazólio poderá ser usado para determinar a viabilidade de sementes com vantagem em relação ao teste de germinação, visto que, pode se obter em laboratório resultados rápidos e confiáveis em curto período de tempo (Mendonça et al., 2001).

A eficácia do teste em avaliar o vigor e a viabilidade das sementes está relacionada à aplicação de metodologias apropriadas para cada espécie, de modo a definir as condições mais apropriadas para o preparo, pré-condicionamento e coloração das sementes. Na etapa de preparo do teste, o período e a temperatura de pré-condicionamento são fatores essenciais.

A temperatura utilizada para o précondicionamento pode ter efeito expressivo na duração do teste. Para se obter coloração mais rápida recomenda-se colocar as sementes em recipientes com solução de tetrazólio, nas temperaturas entre 35 e $40^{\circ} \mathrm{C}$ (Bhéring et al., 1996; França-Neto et al., 1998). A diminuição no tempo de execução do teste pode ser obtida com o aumento da temperatura durante a etapa de pré-condicionamento, uma vez que temperaturas elevadas aumentam a velocidade de embebição da semente (Costa et al., 1998).

Para muitas espécies é necessário um preparo para expor os tecidos do embrião para permitir melhor absorção da solução de tetrazólio e facilitar a avaliação (Brasil, 2009). Os métodos mais utilizados para realizar o preparo antes da coloração são a punção, o corte e a retirada do tegumento (Zucareli et al., 2001). A remoção do tegumento, após o préumedecimento, pode permitir maior uniformidade e rapidez no desenvolvimento da coloração. Entretanto, os resultados podem ser alterados em virtude da eventual ocorrência de danos ao embrião, durante essa remoção.

No caso de sementes de Gleditschia amorphoides Taub. (Fogaça et al., 2006) e Erythrina velutina Willd. (Guedes et al., 2007), recomenda-se a escarificação das sementes na região oposta ao eixo embrionário, até a pequena exposição dos cotilédones, com posterior imersão em água para facilitar a remoção do tegumento e exposição dos embriões.

Apesar da importância, pela rapidez e precisão na determinação da viabilidade e do vigor, o teste de tetrazólio tem o uso ainda restrito a algumas espécies como Phaseolus vulgaris L. (Bhéring et al., 1996), Genipa americana L. (Nascimento \& Carvalho, 1998), Glycine max (L.) Merrill (Costa et al., 1998), Cordia trichotoma (Vellozo) Arrabida ex Steudel (Mendonça et al., 2001), Albizia hasslerii (Chodat) Burr. (Zucareli et al., 2001), abobrinha (Barros et al. 2005), Gleditschia amorphoides Taub. (Fogaça et al., 2006), Lafoensia pacari St. Hil. (Mendonça et al., 2006) e Erythrina velutina Willd. (Guedes et al., 2007).

Baseado no exposto, esse trabalho teve como objetivo estabelecer procedimentos de préumedecimento e coloração, para padronização do teste de tetrazólio na avaliação da viabilidade de sementes de Amburana cearensis. 


\section{MATERIAL E MÉTODO}

O trabalho foi conduzido no Laboratório de Análise de Sementes, do Centro de Ciências Agrárias, da Universidade Federal da Paraíba, em Areia - PB. O experimento foi realizado com um lote de sementes provenientes de frutos que foram coletados em 8 árvores matrizes, no município de Patos - PB, no início da deiscência. Logo após a coleta os frutos, foram beneficiados por meio de debulha manual, realizando-se as seguintes determinações:

\section{Teste de germinação}

Foram utilizadas 100 sementes intactas (sem escarificação), as quais foram divididas em quatro repetições de 25 e colocadas para germinar em substrato de papel toalha, o qual foi organizado na forma de rolo e umedecido com água destilada equivalente a três vezes o peso do papel seco (Brasil, 2009) e mantidas em câmaras de germinação, em temperatura de $30^{\circ} \mathrm{C}$. Nas avaliações adotou-se 0 critério de plântulas normais (Brasil, 2009), com contagens efetuadas a partir do oitavo até o 21 이a após instalação do teste.

\section{Preparo das sementes antes da coloração}

\section{Pré-umedecimento das sementes}

O pré-umedecimento (hidratação) pode ser necessário para algumas espécies e altamente recomendado para outras. No caso da $A$. cearencis analisou-se a necessidade de pré-umedecimento para facilitar a exposição do embrião à ação do tetrazólio. Para esta análise foram utilizadas sementes intactas, ou seja, com o tegumento sem ruptura alguma (sem escarificação) e sementes escarificadas (lixadas) manualmente com lixa d'água № 80 na região oposta ao eixo embrionário até pequena exposição dos cotilédones.

As sementes intactas (sem escarificação) e escarificadas (lixadas) foram imersas diretamente em solução de tetrazólio nas concentrações de 0,025 ; 0,$05 ; 0,075$ e $1,0 \%$, na temperatura de $40^{\circ} \mathrm{C}$, por 12 e $24 \mathrm{~h}$, para verificar se era necessário a remoção (total) do tegumento para que houvesse a coloração. Estes testes pré-eliminares serviram como testemunha para justificar a necessidade ou não de um pré-umedecimento e posterior remoção total do tegumento. Como não se verificou absorção da solução de tetrazólio pelas sementes (sem escarificação e escarificadas), então se procedeu com a análise de métodos de pré-umedecimento que facilitasse a extração do tegumento e exposição dos embriões, para posterior coloração em solução de tetrazólio (Figura 1).

O pré-umedecimento foi dividido em duas etapas como mostra a Figura 1, com o objetivo de hidratar o tegumento (amolecer) e assim promover a remoção adequada. Na primeira etapa foram utilizadas sementes intactas (sem escarificação) e na segunda etapa sementes escarificadas (lixadas).

Primeira etapa - sementes intactas (sem escarificação): a - imersão das sementes diretamente em água destilada por 12, 24, 36 e 48 horas a 35 e $40^{\circ} \mathrm{C}$; b - embebição em papel toalha, o qual foi organizado na forma de rolo e umedecido com água destilada na quantidade equivalente a três vezes o peso seco do papel, por 12, 24, 36 e 48 horas nas temperaturas de 35 e $40^{\circ} \mathrm{C}$. Segunda etapa sementes escarificadas (lixadas): a - imersão das sementes diretamente em água destilada por 12, 24 , 36 e 48 horas a 35 e $40^{\circ} \mathrm{C}$; b - embebição em papel toalha, o qual foi organizado na forma de rolo $e$

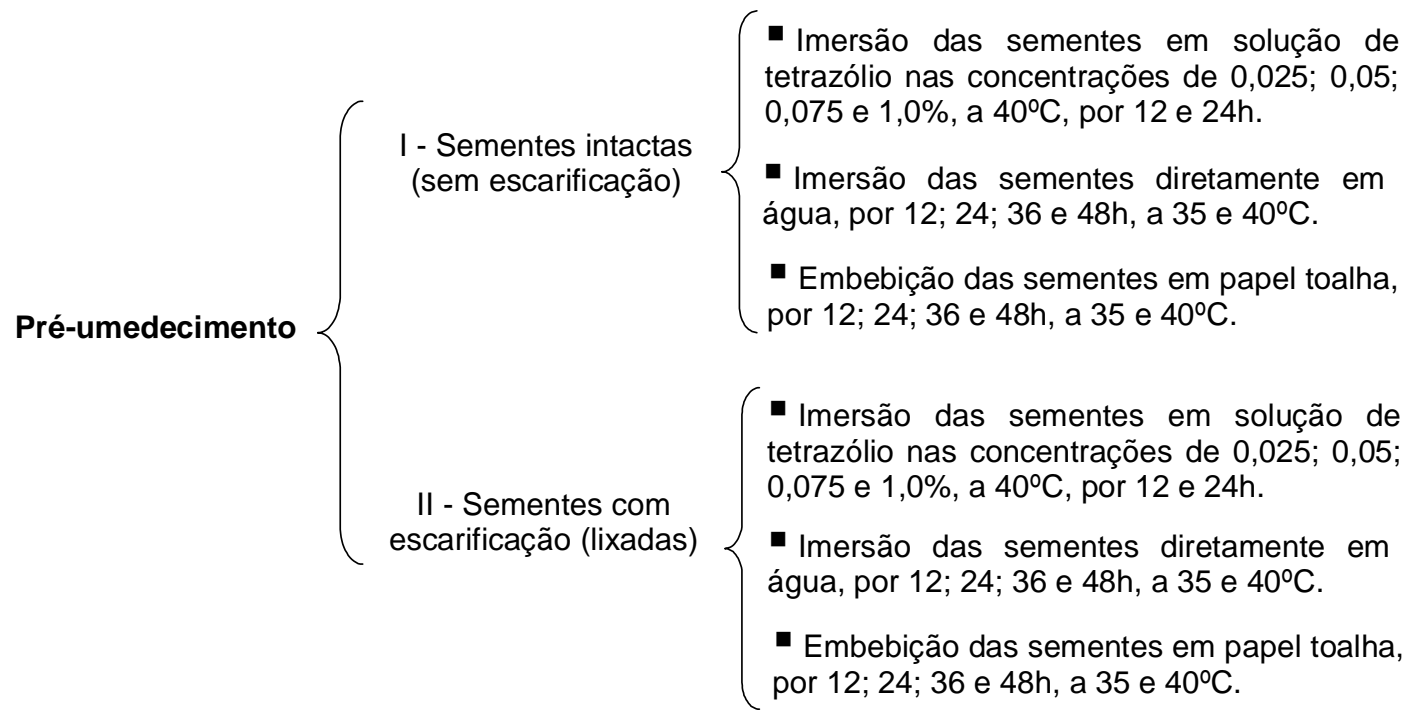

FIGURA 1. Diagrama dos tratamentos de pré-umedecimento das sementes de Amburana cearensis (Allemão) A.C. Smith, antes da coloração. 
umedecido com água destilada na quantidade equivalente a três vezes o peso seco do papel, por $12,24,36$ e 48 horas nas temperaturas de 35 e $40^{\circ} \mathrm{C}$.

\section{Exposição dos tecidos para coloração}

Após a aplicação dos métodos de préumedecimento, os tegumentos foram retirados manualmente, evitando-se danos aos embriões. De acordo com a facilidade de remoção do tegumento determinou-se a viabilidade dos métodos computandose os percentuais de sementes viáveis e inviáveis, sendo consideradas inviáveis aquelas cuja extração do tegumento não foi possível ou que apresentava danos no embrião devido à dificuldade na extração. Para verificar se houve danos na extração do tegumento, as sementes foram colocadas em solução de tetrazólio na concentração de $0,05 \%$ e o número de sementes viáveis e inviáveis foi expresso em porcentagem.

\section{Coloração das sementes}

Após a determinação do método de préumedecimento mais adequado de extração dos tegumentos e exposição dos embriões, testaram-se diferentes concentrações temperaturas para coloração das sementes. Os embriões foram colocados em solução de tetrazólio nas concentrações de 0,025; 0,05; 0,075 e 1,0\% e mantidos no escuro nas temperaturas de 35 e $40^{\circ} \mathrm{C}$. Foram utilizadas quatro repetições de 25 sementes para cada tratamento.

Avaliou-se a cada uma hora, durante oito horas, o período mais adequado para o desenvolvimento da coloração para cada concentração da solução de tetrazólio e temperatura de exposição. As amostras foram retiradas e avaliadas, seguindo este procedimento até que os tecidos (cotilédones e eixo embrionário) atingissem intensidade e uniformidade da coloração.

Após o desenvolvimento da coloração, os embriões foram lavados em água corrente e deixados submersos em água até o momento da avaliação, cerca de 30 minutos. Para cada tratamento, avaliouse o padrão de coloração apresentado pelas sementes: I - vermelho-brilhante ou rosa (tecido vivo e vigoroso); II - vermelho-carmim forte (tecido deteriorado); III - branco-leitoso (tecido morto), conforme França Neto et al. (1988).

\section{RESULTADO E DISCUSSÃO}

Com o teste de germinação verificou-se que as sementes apresentaram germinação de $96 \%$, evidenciando que as sementes apresentavam alta viabilidade.

Em ensaio precedente, constatou-se que as sementes intactas (sem escarificação) imersas diretamente na solução de tetrazólio, nas concentrações 0,$025 ; 0,05 ; 0,075$ e $1,0 \%$, por 12 e 24 horas a 35 e $40^{\circ} \mathrm{C}$, não submetidas a qualquer pré-umedecimento, absorveram a solução de tetrazólio numa quantidade mínima, concentrandose a coloração próxima ao hilo apenas, independentemente das concentrações da solução de tetrazólio e do tempo de exposição estabelecido. Para muitas espécies recomenda-se a retirada do tegumento para que ocorra a coloração, sendo algumas delas, Albizia hasslerii (Chodat) Burr. (Zucareli et al., 2001), Gleditschia amorphoides Taub. (Fogaça et al.,2006), Lafoensia pacari St. Hil. (Mendonça et al., 2006) e Erythrina velutina Willd. (Guedes et al., 2007).

As sementes escarificadas (lixadas) e imersas diretamente na solução de tetrazólio nas concentrações 0,025; 0,05; 0,075 e 1,0\%, por 12 e 24 horas, a 35 e $40^{\circ} \mathrm{C}$, apresentaram coloração desuniforme, concentrando-se especialmente na região próxima à área submetida à escarificação ou simplesmente não coloriram, mantendo a coloração original. Por ter colorido parcialmente não foi possível classificar as sementes em viáveis e inviáveis. Esse fato confirma os relatos de Marcos Filho et al. (1987), sobre a necessidade de hidratação prévia das sementes de algumas espécies, antes da exposição à solução de tetrazólio, de forma que ocorra o amolecimento e a ativação do sistema enzimático, permitindo a absorção da solução e o desenvolvimento da coloração uniforme. Desta forma, comprova-se que o tegumento precisa ser retirado totalmente, para que haja coloração uniforme, e como o tegumento da $A$. cearensis é duro, faz-se necessário um préumedecimento que facilite sua remoção.

Para o pré-umedecimento, em que as sementes utilizadas estavam intactas (sem escarificação), verificou-se que dentre os procedimentos testados para a remoção do tegumento, a imersão das sementes em água a $35^{\circ} \mathrm{C}$ por 24 horas foi o método mais eficiente, por possibilitar a remoção do tegumento sem causar danos às sementes, especialmente ao eixo embrionário (Tabela 1). Quando as sementes foram submetidas ao pré-umedecimento em rolo de papel toalha, nas temperaturas de 35 e $40^{\circ} \mathrm{C}$, por 12 , 24, 36 e 48h, verifiou-se que não foi possível a remover o tegumento das sementes totalmente, verificando-se danos que atingiram a parte vascular próxima ao eixo embrionário (Tabela 1). Os danos observados devem ter sido provocado pela força exercida para retirar o tegumento, uma vez que o mesmo não estava bem hidratado (embebição lenta). Considerando que períodos mais longos implicariam em maior tempo gasto para a condução do teste, ficou, então, definido que períodos superiores a 48 horas não seriam examinados. 
TABELA 1. Viabilidade (\%) das sementes intactas (sem escarificação) de Amburana cearensis (Allemão) A.C. Smith submetidas a diferentes métodos de pré-umedecimento.

\begin{tabular}{ccccc}
\hline \multirow{2}{*}{ Período (h) } & \multicolumn{2}{c}{ 35C } & \multicolumn{2}{c}{$\mathbf{4 0} \mathbf{C}$} \\
\cline { 2 - 5 } & Rolo de Papel & Água & Rolo de Papel & Água \\
\hline 12 & 0 & 10 & 0 & 15 \\
24 & 0 & 81 & 0 & 27 \\
36 & 12 & 46 & 41 & 0 \\
48 & 25 & 32 & 52 & 0 \\
\hline
\end{tabular}

$\mathrm{Na}$ Tabela 1, ainda constatou-se que a imersão direta em água por 12 e 24 horas a $40^{\circ} \mathrm{C}$ e por 48 horas a $35^{\circ} \mathrm{C}$, ocasionou alto percentual de sementes mortas, com danos nos eixos embrionários, reduzindo a viabilidade a 15,27 e $32 \%$, respectivamente, provavelmente isto decorre de acentuada velocidade de embebição e falta de oxigenação. A imersão das sementes diretamente em água, a partir de 36 horas na temperatura de $40^{\circ} \mathrm{C}$ provocou morte total das sementes, sendo evidenciado pela coloração brancoleitoso, que caracteriza o tecido morto. De forma diferente, Nascimento \& Carvalho (1998) observaram que, para sementes de Genipa americana L., a imersão por 24 horas, e temperatura de $30^{\circ} \mathrm{C}$ proporcionaram resultados apropriados para avaliação do teste de tetrazólio. Esse fato confirma que o período e tipo de pré-condicionamento são variáveis que devem ser definidos para cada espécie.

A Tabela 2 apresenta os dados relativos ao pré-umedecimento, em que as sementes utilizadas foram escarificadas (lixadas). Dentre os procedimentos testados para a extração do tegumento, a imersão das sementes em água a $35^{\circ} \mathrm{C}$ por 24 horas foi $\mathrm{O}$ método que apresentou maior eficácia, com $98 \%$ das sementes viáveis, ou seja, sem causar danos ao embrião.

A temperatura de $40^{\circ} \mathrm{C}$ não é indicada para a condução do pré-umedecimento, uma vez que este método promoveu o maior percentual de sementes inviáveis, com danos específicos no eixo embrionário. Diferentemente do que foi constatado no presente trabalho, Guedes et al. (2007) relataram em Erythrina velutina Willd. que a escarifição e a embebição por 12 horas a $40^{\circ} \mathrm{C}$ possibilitou a identificação de sementes viáveis e inviáveis.

$\mathrm{Na}$ Tabela 3 constam as avaliações das combinações de temperatura, concentração e período de exposição dos embriões à solução de tetrazólio. Observou-se que a $35^{\circ} \mathrm{C}$, o tempo mínimo para as sementes atingirem coloração adequada foi de oito horas em solução a $0,025 \%$, seis horas a $0,05 \%$, cinco horas a $0,075 \%$ e três horas a $1 \%$. Quando as sementes foram acondicionadas a $40^{\circ} \mathrm{C}$, em solução a $0,05 \%$, em três horas atingiram a coloração adequada, sendo possível realizar as avaliações em curto período de tempo e com menor gasto do sal de tetrazólio. Verificou-se ainda que as sementes de $A$. cearensis, após o pré-umedecimento e preparo desenvolveram coloração adequada em todas as concentrações examinadas. Observou-se que os resultados alcançados com o teste de tetrazólio em A. cearensis podem ser usados para determinação rápida da viabilidade de sementes.

Para realização de teste de tetrazólio em Albizia hasslerii, as sementes embebidas em água destilada por 24 horas a $25^{\circ} \mathrm{C}$, com retirada do tegumento, em reação com solução de tetrazólio $0,1 \%$ por cinco horas, apresentaram coloração

TABELA2. Viabilidade (\%) das sementes escarificadas (lixadas) de Amburana cearensis (Allemão) A.C. Smith, submetidas a diferentes métodos de pré-umedecimento.

\begin{tabular}{ccccc}
\hline \multirow{2}{*}{ Período $(\mathrm{h})$} & \multicolumn{2}{c}{$\mathbf{3 5} \mathbf{C} \mathbf{C}$} & \multicolumn{2}{c}{$\mathbf{4 0}^{\circ} \mathbf{C}$} \\
\cline { 2 - 5 } & Rolo de Papel & Água & Rolo de Papel & Água \\
\hline 12 & 0 & 10 & 0 & 17 \\
24 & 0 & 98 & 12 & 21 \\
36 & 12 & 33 & 53 & 0 \\
48 & 25 & 18 & 69 & 0 \\
\hline
\end{tabular}

Rev. Bras. PI. Med., Botucatu, v.12, n.1, p.120-126, 2010. 


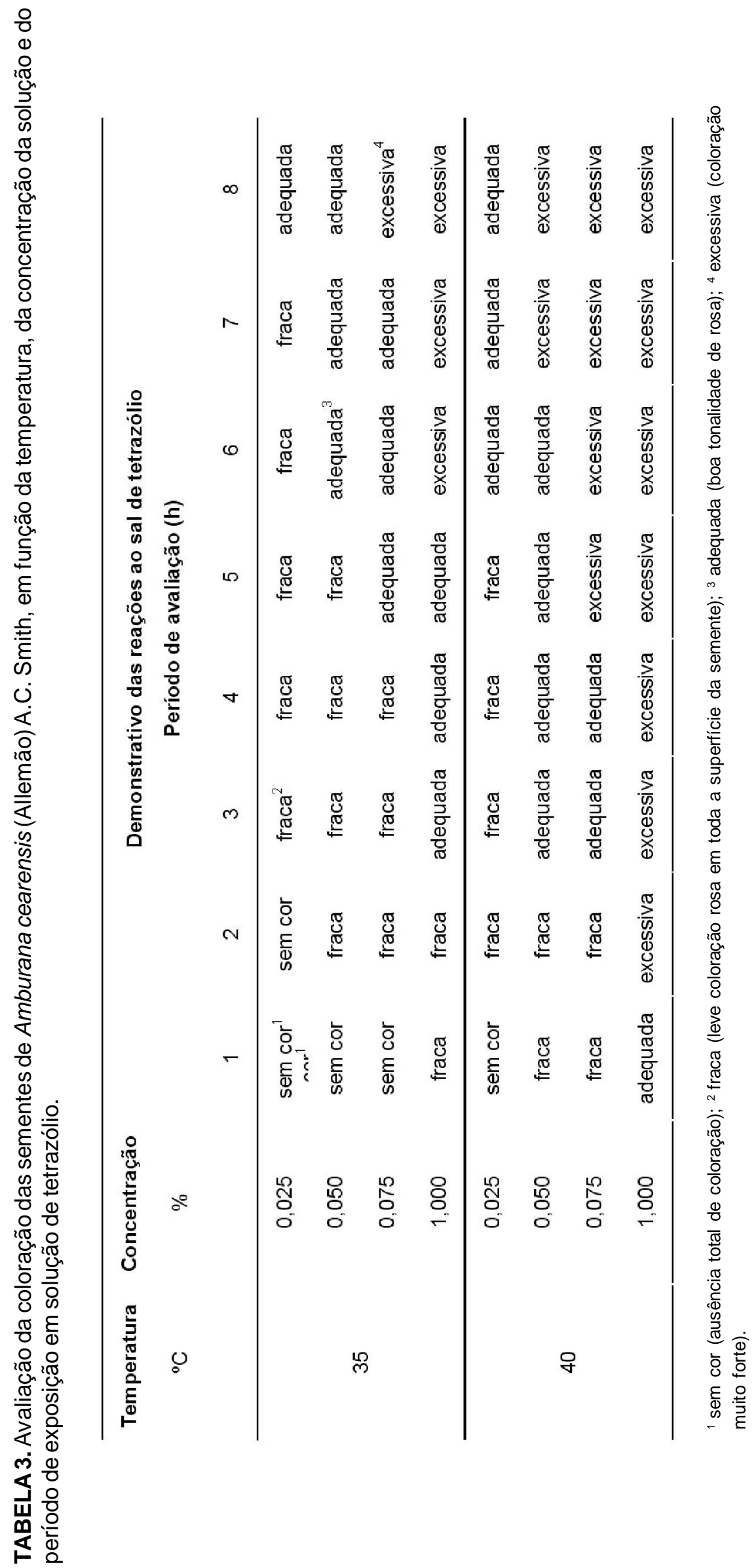

Rev. Bras. Pl. Med., Botucatu, v.12, n.1, p.120-126, 2010. 
adequada possibilitando a identificação e diferenciação de tecidos, com todas as sementes apresentando coloração uniforme (Zucareli et al., 2001). Para Gleditschia amorphoides Taub., Fogaça et al. (2006) recomendaram que as sementes fossem escarificadas mecanicamente, embebidas em água destilada por 48 horas, com posterior retirada do tegumento e exposição à solução de tetrazólio $0,075 \%$ por 3 horas a $35^{\circ} \mathrm{C}$. Sementes de Erythrina velutina Willd. escarificadas e embebidas por 12 horas a $40^{\circ} \mathrm{C}$, com retirada do tegumento, imersas em solução de tetrazólio a $0,05 \%$ por três horas apresentaram, segundo Guedes et al. (2007), coloração ideal, possibilitando a identificação daquelas viáveis e inviáveis.

O teste de tetrazólio nas sementes de $A$. cearensis deve ser realizado com o pré-umedecimento das sementes escarificadas (lixadas) e imersas diretamente em água por 24 horas, na temperatura de $35^{\circ} \mathrm{C}$, para posterior retirada total do tegumento. E para atingir a coloração ideal os embriões devem ser imersos em solução de tetrazólio a $0,05 \%$ por 3 horas, a $40^{\circ} \mathrm{C}$.

\section{REFERÊNCIA}

BARROS, D.I. et al. Uso do teste de tetrazólio para avaliação da qualidade fisiológica de sementes de abobrinha. Revista Brasileira de Sementes, v.27, n.2, p.165-71, 2005.

BERG, M.E.V.D. Formas atuais e potenciais de aproveitamento das espécies nativas exóticas do Pantanal Mato-Grossense. In: SIMPÓSIO SOBRE RECURSOS NATURAIS E SÓCIOS ECONÔMICOS DO PANTANAL, 3., 1986, Corumbá. Anais... Brasília: Embrapa, 1986. p.131-6. (EMBRAPA-CPAC. Documentos, 5).

BHÉRING, M.C. et al. Avaliação da viabilidade e do vigor das sementes de feijão-de-vagem (Phaseolus vulgaris L.) pelo teste de tetrazólio. Viçosa: UFV, 1996. 27p.

BRASIL. Ministério da Agricultura, Pecuária e Abastecimento. Regras para análise de sementes. Brasília, DF: Mapa/ACS, 2009. 399p.

CANUTO K.M. Contribuição ao conhecimento químico de plantas do Nordeste: Herisantia tiubae (K. Schumann) Briz e Amburana cearensis (Fr. Allem.) A.C. Sm. 2002. 123p. Dissertação (Mestrado em Química) - Universidade Federal do Ceará, Fortaleza.

COSTA, N.P. et al. Avaliação de metodologia alternativa para o teste de tetrazólio para sementes de soja. Scientia Agricola, v.55, n.2, p.302-12, 1998.

FOGAÇA, C.A. et al. Aplicação do teste de tetrazólio em sementes de Gleditschia amorphoides Taub. Caesalpinaceae. Revista Brasileira de Sementes, v.28, n.3, p.101-7, 2006.

FRANÇA-NETO, J.B.; KRZYZANOWSKI, F.C.; COSTA, N.P. $O$ teste de tetrazólio em sementes de soja. Londrina: EMBRAPA-CNPSo, 1998. 72p.

FRANÇA-NETO, J.B. et al. Metodologia do teste de tetrazólio em sementes de soja. Londrina: EMBRAPACNPSo. 1988. 60p.

GUEDES, R.S. et al. Pré-condicionamento para teste de tetrazólio em sementes de Erythrina velutina Willd. In: CONGRESSO NACIONAL DE BOTÂNICA, 58., 2007, São Paulo. Resumos... São Paulo: CNB. 2007. CD-ROM. 2007. IBAMA. Instituto Brasileiro de Meio Ambiente e dos Recursos Naturais Renováveis. Portaria no $37-\mathrm{N}$ de 3 de abril de 1992. Lista oficial de espécies da flora brasileira ameaçada de extinção. Disponível em: <http://www. ibama.gov.br>. Acesso em: dez. 2008.

LORENZI, H. Árvores brasileiras: manual de identificação e cultivo de plantas arbóreas nativas do Brasil. Nova Odessa: Plantarum, 1992. 382p.

LORENZI, H.; MATOS, F.J.A. Plantas medicinais no Brasil: nativas e exóticas. São Paulo: Instituto Plantarum de Estudos da Flora Ltda., 2002. 512p.

MARCOS-FILHO, J.; CICERO, S.M.; SILVA, W.R. Avaliação da qualidade das sementes. Piracicaba: FEALQ, 1987. 230p.

MENDONÇA, E.A.F.; RAMOS, N.P.; PAULA, R.C. Viabilidade de sementes de Cordia trichotoma (Vellozo) Arrabida ex Steudel (louro-pardo) pelo teste de tetrazólio. Revista Brasileira de Sementes, v.23, n.2, p.64-71, 2001. MENDONÇA, E.A.F; COELHO, M.F.B; LUCHESE, M. Teste de tetrazólio em sementes de mangaba-brava (Lafoensia pacari St. Hil. - Lythraceae). Revista Brasileira de Plantas Medicinais, v.8, n.2, p.33-8, 2006.

NASCIMENTO, W.M.O.; CARVALHO, N.M. Determinação da viabilidade de sementes de jenipapo (Genipa americana L.) através do teste de tetrazólio. Revista Brasileira de Sementes, v.20, n.2, p.231-5, 1998.

ZUCARELI, C. et al. Preparo e coloração de sementes de farinha-seca (Albizia hasslerii (Chodat) Burr.) para o teste de tetrazólio. Revista Brasileira de Sementes, v.23, n.2, p.186-91, 2001. 